\title{
Univariate Statistics of the RCPs Forced ET-SCI Based Extreme Climate Indices Over Pakistan
}

\author{
Ahmad Khan Burhan ${ }^{1 *}$, Azmat Hayat Khan ${ }^{1}$, Syed Ahsan Ali Bukhari ${ }^{1}$, Khurram Riaz ${ }^{1}$ \\ ${ }^{1}$ Pakistan Meteorological Department, PAKISTAN \\ *Corresponding Author: burhanahmadkhan@gmail.com
}

Citation: Burhan, A. K., Khan, A. H., Bukhari, S. A. A. and Riaz, K. (2021). Univariate Statistics of the RCPs Forced ET-SCI Based Extreme Climate Indices Over Pakistan. European Journal of Sustainable Development Research, 5(3), em0166. https://doi.org/10.21601/ejosdr/11091

ARTICLE INFO

Received: 5 Apr. 2021

Accepted: 26 Jun. 2021

\begin{abstract}
Numerical summaries of univariate climatic records, such as temperature and precipitation, are useful for making quantitative decisions for mitigation and adaptation measures. Climate simulations and projections often contain values that lie far away from substance of the data. These values can bias the summary statistics away from values representative for majority of the sample. This problem can be avoided by selecting ensembles approach as well as by using statistics that are resistant to the presence of such outliers. Hence, in addition to typical statistics, resistant statistics are used to investigate spatiotemporal changes in temperature and precipitation extremes over a versatile agro-climatic featured country of Pakistan, by engaging the National Aeronautics and Space Administration Earth Exchange Global Daily Downscaled Projections (NEX-GDDP) dataset under two Representative Concentration Pathways (RCPs) 4.5 and 8.5 that provides statistically downscaled Coupled Model Inter-comparison Project Phase 5 (CMIP5) climate baseline (1971-2000) and projections (20212050) based on Expert Team on Sector-specific Climate Indices (ET-SCI) method. The results show the following: (a) Shifts in the univariate count statistics under the RCP8.5 are highly prominent with 0.81 degrees deviation in 5th percentile and with a substantial 1.86 degrees deviation in the 95th percentile of the maximum of daily maximum temperature over the projected time series. (b) Standard deviation of historical summer days is placed at 3.7 days with a consistent change under the RCP4.5 emission scenario. Nevertheless, the standard deviation of the summer days hikes by 5.9 days under the RCP8.5 emission scenario. (c) A distressing condition is comprehended under the RCP8.5 emission scenario where changes of 16.5 percent in the 5 th and of 19.7 percent in the 95th percentiles are revealed in the warm nights future projections. (d) The maximum rate of simple daily intensity of precipitation in the historical period exists at $0.2 \mathrm{~mm}$ /day, however, the RCP4.5 emission scenario thrusts that up to $0.6 \mathrm{~mm} /$ day in the projection period. (e) Under the RCP8.5 emission scenario, the standard deviation inflates by 36.4 days while range digresses by an enormous 95 days in the projection period of the consecutive dry days. The outcomes are of applied practice in improving local approaches for hydro-reservoirs and eco-environment controlling, especially in the diverse climatic region of Pakistan.
\end{abstract}

Keywords: NEX-GDDP, RCPs, CMIP5, ET-SCI

\section{INTRODUCTION}

It is widely acknowledged that atmospheric greenhouse gases have contributed to global warming in past and current century (Aziz et al., 2021). Pertaining to regional effects, Pakistan is deemed as one of the most vulnerable countries of the world to extreme climate (Khan et al., 2019). Climate change is explicitly varying natural systems and posing impacts on climatically heterogeneous expanses of Pakistan. Climate change can be considered as an anomaly that explicitly varies in different stretches of terrestrial realm, yet, variation in climate extremes can dispense even more severe and unforeseen impacts in Pakistan (Ali et al., 2019). In light of changing climate, Ali et al. (2021) warns that warm and wet conditions may prevail in future projections of Pakistan. Precipitation variability augmented with surging frequency and intensity of climate extremes have become two of the most imperative and critical issues for policymakers since the end of $20^{\text {th }}$ century (Rehman et al., 2020). Such prevalent alterations in extreme climate records are of significant importance, especially, for climate risk management (Saleem et al., 2021). In view of liability of Pakistan's economy to extreme climatic events, demand for robust prognostications of future variability in the extremes is essential for stakeholders and policymakers (Rehman et al., 2020). With evident variation in climate of Pakistan, evaluating the long-term climatic deviations is of primary significance for comprehending the impact of climate change (Bhatti et al., 2020). 
Sustainable development via adaptation and mitigation in a region can be attributed to future configurations of influential extremes over vulnerable regions. Extent and duration of vulnerability to hazards of climate extremes is not homogeneous, and hence higher variations in temperature and precipitation are destined to trigger correspondingly higher risks in affected regions (Ahmed et al., 2019; Qaisrani et al., 2018). Ali et al. (2019) attempted to detect changes in climate extremes using Coupled Model Intercomparison Project Phase 5 (CMIP5) based 14 General Circulation Models (GCMs) under Representative Concentration Pathways RCP4.5 and RCP8.5 with application of Expert Team on Climate Change Detection and Indices (ETCCDI) over sub-regions of Pakistan. In another attempt, Sajjad and Ghaffar (2019) explored the projected extreme climate indices using NASA Earth Exchange Global Daily Downscaled Projections (NEX-GDDP) dataset under the two RCPs with application of 3 GCMs for investigation of possible shifts over Pakistan. A study conducted by Bhatti et al., (2020) investigated the variability of extreme precipitation events by assessing trends in precipitation extreme indices using daily historical precipitation data over Pakistan. Very recently, Ali et al. (2021) explored future projections of temperature and precipitation by analysing future extremes projected by using the standard indices from the ETCCDI over districts of Pakistan situated in the Hindu Kush region. Towards Northwest Himalayas (Pakistan), Aziz et al., (2021) studied variability of temperature extremes using the ETCCDI methods for early $21^{\text {st }}$ century. Over monsoon dominant region of Pakistan, Saddique et al. (2020) investigated trends of precipitation and temperature extremes by using ensemble mean of 3 GCMs under the two RCPs with application of the ETCCDI for second half of the $21^{\text {st }}$ century in the Jhelum River Basin. Towards eastern districts of Pakistan, Riaz et al., (2020) studied outlook of 4 CMIP5 GCMs for the ETCCDI based extremes for historical (1850-2005) and future periods (2020$2100)$ under the two RCPs. The ETCCDI based extremes were also studied over trans-boundary river basin of India and Pakistan by using four regional climate models (RCMs) future period (2020-2095) under the two RCPs (Aslam et al., 2020). Based on a fine resolution single GCM of the CMIP5, the ETCCDI indices under the two RCPs were also calculated for future period relative to a reference period over Pakistan (Rehman et al., 2020).

Provided that the climate shifts inevitably, it is of utmost importance to detect intensity and duration of key climate indicators in projected environments of the country. As reported in a recent study over Pakistan, there is a projected increase in frequencies and magnitudes for warm temperature extremes and the corresponding trends of maximum and minimum temperature extremes are greater than the mean temperature trend (Ali et al., 2019). There are strong evidences of increasing trend in the mean maximum temperature and summer days from North to South in Pakistan, which have the potential to enhance frequency and intensity of heat waves in the region. As reported by Saleem et al. (2021), principal component analysis showed a robust increase in the intensity and frequency of extreme temperatures over Pakistan. In fact, there is a projected increase of more than 20 days in summer days index of Pakistan (Sajjad and Ghaffar, 2019). Saddique et al. (2020) also endorsed Sajjad and Ghaffar (2019) by reporting significant surges in warm nights, summer days and warmest day indices in Pakistan. The eastern extents have also been reported to show significant increases in summer days with additional magnitude increase in warmest days over Pakistan (Riaz et al., 2020). In another analysis, Aziz et al. (2021) showed that frequency of summer days had increasing trends in the Southwest region of Northwest Himalayas (Pakistan) and that the maximum value of daily maximum temperature had increased in the foothill area of the region.

Not only the temperature but the precipitation extremes have also remained vulnerable with most of the sub-regions across Pakistan showing a higher increase in total annual precipitation and intense precipitation events (Ali et al., 2019). It is perceived that patterns of climate extremes have allegedly been altered due to climate change effects. The effects, owing to their variability in both high magnitude and low magnitude pulses, has remained heterogeneous throughout the country. Moreover, indicators of wet and dry climate have shown high sensitivity to climate change effects over Pakistan. Since hydrological cycle and water balances are disturbed in presence of climatic extremes, they ultimately affect water and food security under warming scenarios (Betts et al., 2018; Watanabe et al., 2018). Despite the increase in total precipitation, numbers of consecutive dry days are increasing which can give rise to drought conditions (Ali et al., 2019). Also, linear trend of precipitation extremes including simple daily intensity index have an increasing tendency along historical period which have provided a credible signal of the current phenomena of climate change and variability that altered the precipitation regime of Pakistan (Bhatti et al., 2020). Rehman et al. (2020) further showed that flood related extreme indices were projected to increase over Pakistan.

The overall temperature gradient is sharp and distribution of precipitation is diverse due to high altitude peaks graduating from South to North of Pakistan. Reported by Germanwatch, vulnerability index of Pakistan has remained among the top 10 countries severely impaired by climate change. Impact of global changes in the climate regime are far reaching and thus clearly affects sustainability aspects at regional and local scales. Evidently, anthropogenic triggers mainly associated with the $\mathrm{CO}_{2}$ emissions - have rendered significant increases in global warming which has forced both temperature and precipitation related extremes to recur with higher frequencies and amplitudes at global and regional scales (Myhre et al., 2019; Mukherjee, 2018; Shultz, 2019). Owing to significantly observed recurrences of climate extremes in recent years, higher consideration is given to concerns related to climate change. Both the InterGovernmental Panel on Climate Change (IPCC) and the series of Conference of Parties (COP) have provided vision to governments to take reforms in order to limit emissions-forced global warming to 1.5 and 2.0 degrees. However, much intervention is needed to reach such targets since global indicators show worrisome figures by the end of $21^{\text {st }}$ century. Extreme events that can trigger impacts, hence need investigation for their potential variation over Pakistan.

While there are studies on climate extremes that have been directed for representation of climatic extremes in Pakistan at regional and national scales, yet only a few have used high resolution climate models for this particular region where 
adversity and intricacy of regional terrain is highly responsive of changes in climate attributes. Moreover, engaged number of climate models have remained limited in such studies. With the intention of obtaining robust results, it is advised to use ensemble of several climate models so as to minimize systematic biases associated with uncertainties for suitable for policy making (see e.g., Saeed and Athar, 2017). In the present research work, we dispense a multi-model ensemble of NEXGDDP data set to determine future projections of the World Meteorological Organization's (WMO's) Expert Team on Sector-Specific Climate Indices (ET-SCI) based extremes under the two RCPs at $0.25^{\circ} \times 0.25^{\circ}$ resolution and composed of output from Coupled Model Inter-comparison Project phase 5 (CMIP5) derived GCMs. Unlike the ETCCDI, the ET-SCI has published sectors of relevance to each index determined by consultation with sector representatives of health, agriculture, food security, water resources and hydrology (https://climpact-sci.org/assets/climpact2-user-guide.pdf).

Moreover, contrary to the traditional approach to determine trends and means of the extreme climate, we argue to present univariate statistics of the ET-SCI based extremes for the first time over Pakistan. We further propose to deploy robustness in our results by engaging 20 GCMs ensemble for the detection of future patterns of extremes over heterogeneous relief of Pakistan.

The novelty of current research resides with three important aspects - (1) Till date, none of the studies over Pakistan envisaged the ET-SCI based extreme climate indices which encapsulates an extended compendium of core and noncore climate indices, though several researchers have attempted to use an older version, i.e., the ETCCDI as focus of their studies over Pakistan. (2) None of the studies, till now, have used a large ensemble of $20 \mathrm{GCMs}$ of the high resolution NEX-GDDP for projection of extremes over Pakistan. (3) One of our main focuses in this study is to reflect both resistant (the median or the inter-quartile range) and non-resistant (the mean, the standard deviation and the higher percentiles) statistics of the climate extremes. Since the non-resistant measures of centre and spread are more easily influenced by outliers or skewness, the resistant measures are not affected as much, and hence can be used for data that has outliers or is skewed. In this way, we could check for shifts in the climatic extremes with or without the presence of outliers and skewness in the engaged data. To our knowledge, focus of studies over Pakistan had remained restricted to project trends and mean changes only, using smaller number of GCM ensembles and no research study has till now applied the current approach to address both resistant and non-resistant shifts in the climatic extremes over Pakistan.

\section{LOCALITY FEATURES}

Pakistan is located between latitudes $24^{\circ} \mathrm{N}-37^{\circ} \mathrm{N}$ and longitudes $60^{\circ} \mathrm{E}-75^{\circ} \mathrm{E}$ in southwest Asia and encompasses an area of $796,000 \mathrm{~km}^{2}$ (Figure 1). It borders with the India and Arabian Sea in the east, Afghanistan and Iran in the west and China in the north. The climate of Pakistan is very diverse in terms of temperature and precipitation. On one side it is mostly arid to semiarid, followed by warm summers and icy winters with extreme temperature variations, while on the other side the southern slopes of the Himalayas and the sub-

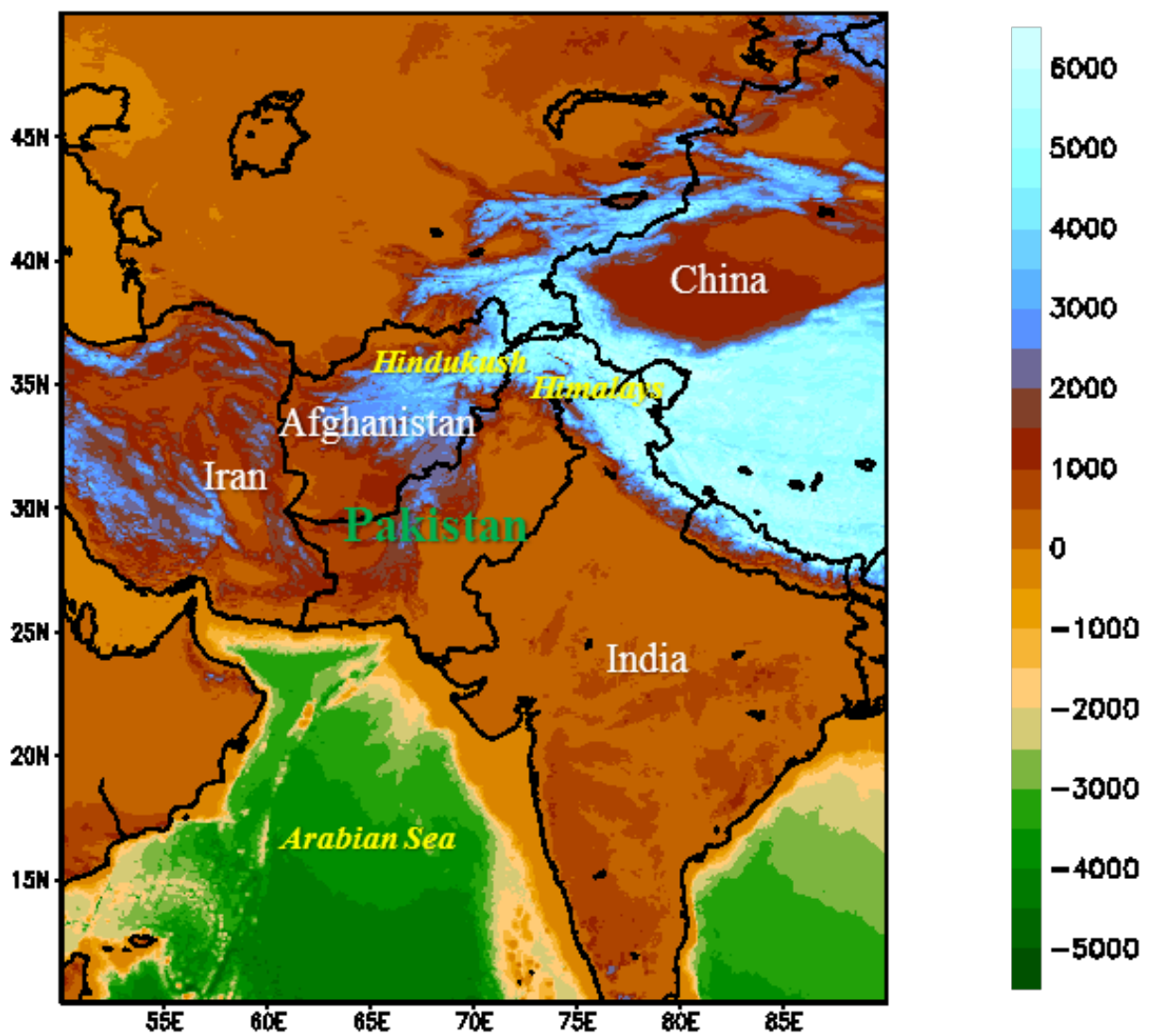

Figure 1. Geo-spatial and relief $(\mathrm{m})$ information of the study region, Pakistan 
Table 1. Details of CMIP5 derived NEX-GDDP climate models used in this study

\begin{tabular}{cccc}
\hline Serial & Model & Serial & Model \\
\hline 1 & ACCESS1-0 & 11 & CESM1-BGC \\
\hline 2 & INMCM4 & 12 & MIROC5 \\
\hline 3 & BCC-CSM1-1 & 13 & CNRM-CM5 \\
\hline 4 & IPSL-CM5A-LR & 14 & MPI-ESM-LR \\
\hline 5 & BNU-ESM & 15 & CSIRO-MK3-6-0 \\
\hline 6 & IPSL-CM5A-MR & 16 & MPI-ESM-MR \\
\hline 7 & CanESM2 & 17 & GFDL-CM3 \\
\hline 8 & MIROC-ESM & 18 & MRI-CGCM3 \\
\hline 9 & CCSM4 & 19 & GFDL-ESM2G \\
\hline 10 & MIROC-ESM-CHEM & 20 & NorESM1-M
\end{tabular}

mountain region receives annual rainfall ranges from $760 \mathrm{~mm}$ to $2000 \mathrm{~mm}$ (Abbas et al., 2020). The south eastern parts of country receives rainfall through the southwest summer monsoon (from June to September) which contributes to about $60 \%$ of the annual rainfall, while the south western parts of the realm receive rainfall through western weather disturbances in winter (from December to March). About 75 percent of the country receives less than $250 \mathrm{~mm}$ rainfall annually (Chaudhary et al., 2009). The northern parts of the country have snow covered gigantic peaks such as Karakoram Range 2 (8,611 meters high), and the largest glaciers including Siachen (70 km long) and Biafo $(63 \mathrm{~km})$ that feed the Indus River and some of its tributaries. The southern and western parts of the country include Baluchistan Plateau and Indus River basin plain. Baluchistan plateau is a dry region and most of its north western part is consists of desert because of less rainfall which is less than $210 \mathrm{~mm}$ per year. Indus river basin plain covers $65 \%$ of the total land area of Pakistan, i.e., $520000 \mathrm{~km}^{2}$. The annual mean of rainfall in the Indus plain is around $230 \mathrm{~mm}$ (Chaudhary, 2017). Temperature variation is obvious because of the changing topography in the lower and upper basin of Indus plain. Mean summer temperature of lower basin plain is $42^{\circ} \mathrm{C}-44^{\circ} \mathrm{C}$ and mean winter temperature is $14^{\circ} \mathrm{C}-20^{\circ} \mathrm{C}$. Mean summer temperature of upper Indus basin plain is $23^{\circ} \mathrm{C}-49^{\circ} \mathrm{C}$ and mean winter temperature is $2^{\circ} \mathrm{C}-23^{\circ} \mathrm{C}$ (WCD, 2000).

\section{INGESTED DATA}

Historical and projected daily maximum, minimum temperature and precipitation were acquired from the NEXGDDP dataset (https://cds.nccs.nasa.gov/nex-gddp/) comprised of downscaled climate scenarios for the globe, derived from GCM runs conducted under 21 CMIP5 model simulations. Thrasher et al. (2013) used Bias Correction and Spatial Disaggregation (BCSD) method to generate the NEXGDDP data set for 20 CMIP5 model simulations engaged in this study (Table 1). The period 1970-2000 was used for historical assessment while the period 2021-2050 was used to detect projected changes in the future runs at a high spatial resolution $(0.25 \times 0.25)$ of the NEX-GDDP. The data was post processed on a unix platform with the help of Climate Data Operator (CDO) tool (https://code.mpimet.mpg.de/projects/ cdo) to acquire ensemble mean of all the CMIP5 GCMs involved. Two emission scenarios with the concentration of $\mathrm{CO}_{2}$ as $\sim 550 \mathrm{ppm}$ for RCP4.5 and $\sim 950 \mathrm{ppm}$ for RCP8.5 representing an intermediate emissions scenario and a business as usual emissions scenario in the future respectively
- were taken for detection of possible human triggered climate change impacts on the studied region (see for instance, Burhan, 2018). The ingested NEX-GDDP data has fairly good correlation and consistency with observations over the study area as may be seen in Burhan and Shahid (2017).

\section{METHODOLOGICAL STRUCTURE}

Two main methodological steps cover this study; firstly, the ET-SCI based computation of temperature and precipitation related indices, and secondly, the univariate inferences of the calculated indices for both the resistant and non-resistant statistics.

In the first step, a suite of climate change indices with 03 temperature related indices and 02 precipitation-related indices motivated by the Expert Team on Sector-specific Climate Indices (ET-SCI) were engaged in this study. Detailed definitions of 05 extreme indices are directly listed in Table 2 and further details may also be found in a brief by Ahmad et al. (2020) that illustrated the use of climate indices approach for climate change assessment. Each of the indices represented a group of categories, that is, percentile-based, absolute, threshold, duration and societal impact indices. Based on the daily temperature and precipitation sequences, extreme indices were computed by WMO's Commission for Climatology $(\mathrm{CCl})$ recommended climPACT2 software (https://climpactsci.org/get-started/) to effectively describe annual changes in the intensity, frequency and duration of extreme events (Török et al., 2021).

In the second step, univariate descriptive statistical methods were used to summarize temperature and precipitation data numerically. All statistical data was branded into one of three different types: ranked, discrete and continuous. Measures of central tendency (mean and median) provided information on the most typical value in the data sets. Measures of variation (standard deviation and range) provided information on the spread of the data with respect to mean value. If the distribution of the data was symmetric with no significant outliers, then the mean and standard deviation were preferred. If the distribution of the data was skewed or had significant outliers, then the median was preferred. Based on calculated indices, future differences were computed for several measures of dispersion (including resistant and nonresistant statistics, Table 3) and corresponding shifts in those indices were detected. 
Table 2. Information on climate extreme indices analyzed in this study

\begin{tabular}{|c|c|c|c|c|c|}
\hline Labels & Group & Description & Sector(s) & Impacts & Units \\
\hline TXX & Absolute & Maximum of daily maximum temperature & $\begin{array}{l}\text { Agriculture and food } \\
\text { security }\end{array}$ & $\begin{array}{l}\text { Increased evapotranspiration, more } \\
\text { energy consumption, affecting crop } \\
\text { yield, deterioration of health }\end{array}$ & ${ }^{\circ} \mathrm{C}$ \\
\hline SU25 & Threshold & $\begin{array}{l}\text { Summer days, number of days when the daily } \\
\text { maximum temperature is above } 25^{\circ} \mathrm{C}\end{array}$ & Health & $\begin{array}{l}\text { Increased evapotranspiration, risk } \\
\text { of droughts, affecting crop yield, } \\
\text { deterioration of health }\end{array}$ & Days \\
\hline TN90p & $\begin{array}{l}\text { Percentile- } \\
\text { based }\end{array}$ & Amount of warm nights & Non-core & $\begin{array}{l}\text { Fraction of days with warm night } \\
\text { time temperatures are triggers of } \\
\text { crop damage and heat wave risks }\end{array}$ & $\%$ \\
\hline CDD & Duration & $\begin{array}{l}\text { Consecutive dry days, maximum number of } \\
\text { consecutive days with less than } 1 \mathrm{~mm} \text { of daily } \\
\text { precipitation. }\end{array}$ & $\begin{array}{c}\text { Health, agriculture, food } \\
\text { security, water resources and } \\
\text { hydrology }\end{array}$ & $\begin{array}{c}\text { Water shortage } \\
\text { Crop damage } \\
\text { Triggering of droughts } \\
\end{array}$ & Days \\
\hline SDII & $\begin{array}{c}\text { Societal } \\
\text { impact }\end{array}$ & Simple daily intensity & Non-core & $\begin{array}{l}\text { Land sliding, loss of fertile soil, } \\
\text { reduces yields of major crops }\end{array}$ & $\mathrm{mm} /$ day \\
\hline
\end{tabular}

Table 3. Group of univariate statistics showing information on resistant and non-resistant metrics used in this study

\begin{tabular}{|c|c|c|c|}
\hline Sr. No. & Statistic & State & Explanatory comments \\
\hline 1 & $1 \%$-tile & \multirow{3}{*}{$\begin{array}{l}\text { Non- } \\
\text { resistant }\end{array}$} & 1 percent of the values were smaller than this number and 99 percent of the values were larger \\
\hline 2 & 5\%-tile & & 5 percent of the values were smaller than this number and 95 percent of the values were larger \\
\hline 3 & 10\%-tile & & 10 percent of the values were smaller than this number and 90 percent of the values were larger \\
\hline 4 & 25\%-tile & \multirow{3}{*}{ Resistant } & $\begin{array}{c}\text { lower quartile; } 25 \text { percent of the values were smaller than this number and } 75 \text { percent of the values } \\
\text { were larger }\end{array}$ \\
\hline 5 & 50\%-tile & & $\begin{array}{l}\text { middle data value, } 50 \text { percent of the data values were larger than this number and } 50 \text { percent of the } \\
\text { data were smaller than this number }\end{array}$ \\
\hline 6 & 75\%-tile & & $\begin{array}{c}\text { upper quartile; } 75 \text { percent of the values were smaller than this number and } 25 \text { percent of the values } \\
\text { were larger than this number }\end{array}$ \\
\hline 7 & 90\%-tile & \multirow{8}{*}{$\begin{array}{l}\text { Non- } \\
\text { resistant }\end{array}$} & 90 percent of the values were smaller than this number and 10 percent of the values were larger \\
\hline 8 & 95\%-tile & & 95 percent of the values were smaller than this number and 5 percent of the values were larger \\
\hline 9 & 99\%-tile & & 99 percent of the values were smaller than this number and 1 percent of the values were larger \\
\hline 10 & Minimum & & minimum value \\
\hline 11 & Maximum & & maximum value \\
\hline 12 & Mean & & arithmetic average of the data \\
\hline 13 & Standard Deviation & & square root of variance of the data \\
\hline 14 & Range & & separation between the minimum and maximum value. Range $=$ maximum - minimum \\
\hline 15 & Median & Resistant & $\begin{array}{l}\text { middle data value, } 50 \text { percent of the data values were larger than this number and } 50 \text { percent of the } \\
\text { data were smaller than this number }\end{array}$ \\
\hline
\end{tabular}

\section{RESULTS}

\section{Shifts in the TXX}

Figure 2 shows output of the computed statistics for the TXX. Univariate count analysis of the TXX shows that it establishes its $5^{\text {th }}$ percentile at 0.3 units and its $95^{\text {th }}$ percentile at 0.48 units over the historical time series. Projected changes in the TXX historical univariate count statistics under the RCP4.5 shows shifts of 0.48 units in the $5^{\text {th }}$ percentile and of 0.93 units in the $95^{\text {th }}$ percentile over the projected time series. Shifts in the univariate count statistics under the RCP8.5 are more pronounced with 0.81 units deviation in the $5^{\text {th }}$ percentile and with a massive 1.86 units deviation in the $95^{\text {th }}$ percentile over the projected time series. This significant increase in the percentiles of the TXX indicates shifts in the absolute temperature of both milder and hotter daytime temperature extremes in the future projections of the analyzed region.

Minimum of the TXX in the historical period reaches 0.3 degrees whilst it reaches 0.48 (0.81) degrees under the RCP4.5 (RCP8.5) emission scenario. Maximum of the TXX is also significantly high in the future projections with values escalating from 0.48 degrees in the historical to an added 0.93 degrees under the RCP4.5 and even further to an added 1.86 degrees under the RCP8.5 univariate statistics. Mean of the TXX is 0.42 degrees in the historical but elevates prominently by 0.66 degrees under the RCP 4.5 and by 1.37 degrees under the RCP8.5 emission scenario. Median changes are also evident in the univariate statistics where a change from 0.45 degrees in the historical to an increase of 0.51 degrees under the RCP4.5 and further to an increase of 1.38 degrees under the RCP8.5 is seen in post processed output of the univariate statistics. Significantly high median values indicate that even in the absence of extreme events, congregate of the TXX under the RCP8.5 is likely to propagate more than three times of the historical under the high-end emission scenario.

The TXX historical standard deviation is calculated at 0.08 , however owing to possibly high extreme events in the future, the standard deviation change spreads by 0.2 degrees under the RCP 4.5 and by 0.4 degrees under the RCP8.5 emission scenario. Inter zonal range varies significantly for the TXX with 0.18 degrees in the historical period to an added 0.45 degrees under the RCP4.5 and even further to an added 1.05 degrees under the RCP8.5 emission scenario in the univariate statistics. Increases in the standard deviation and the range of 
$\operatorname{TXX}\left({ }^{\circ} \mathrm{C}\right)$

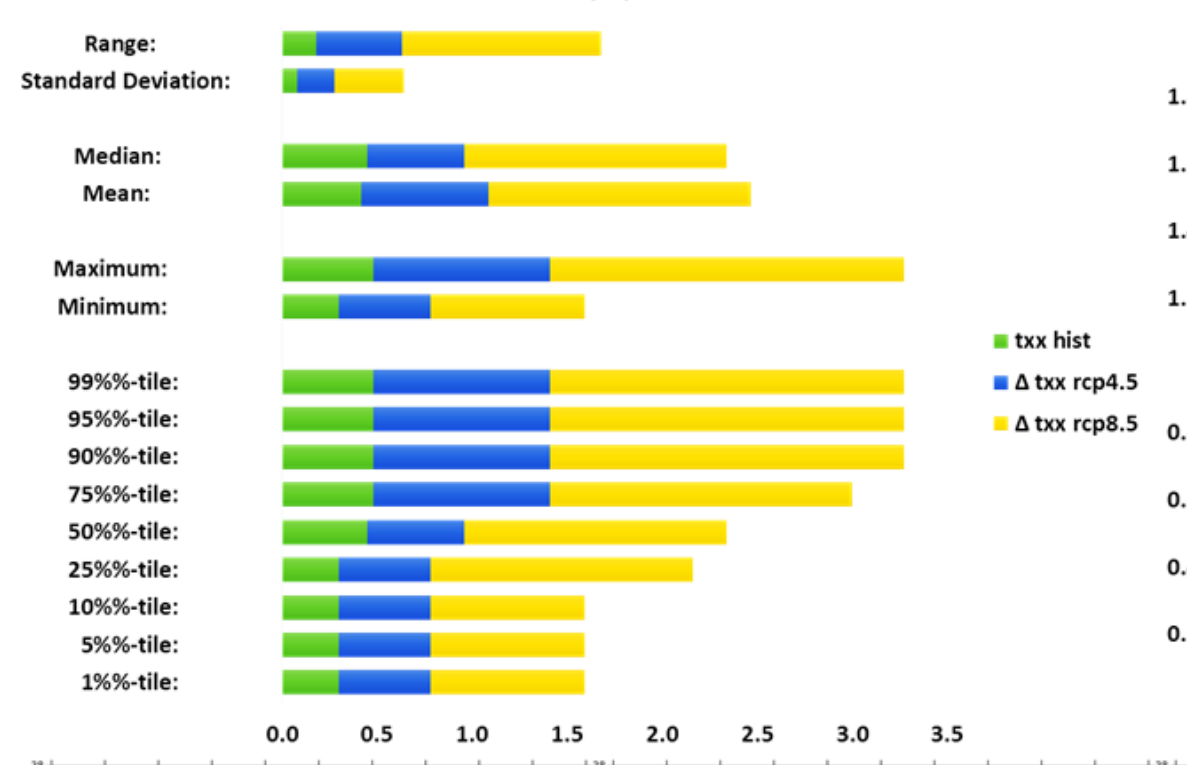

$\Delta$ Absolute Index $\left({ }^{\circ} \mathrm{C}\right)$

2

.8

1.6

4

.2

1

0.6

0.4

0.2

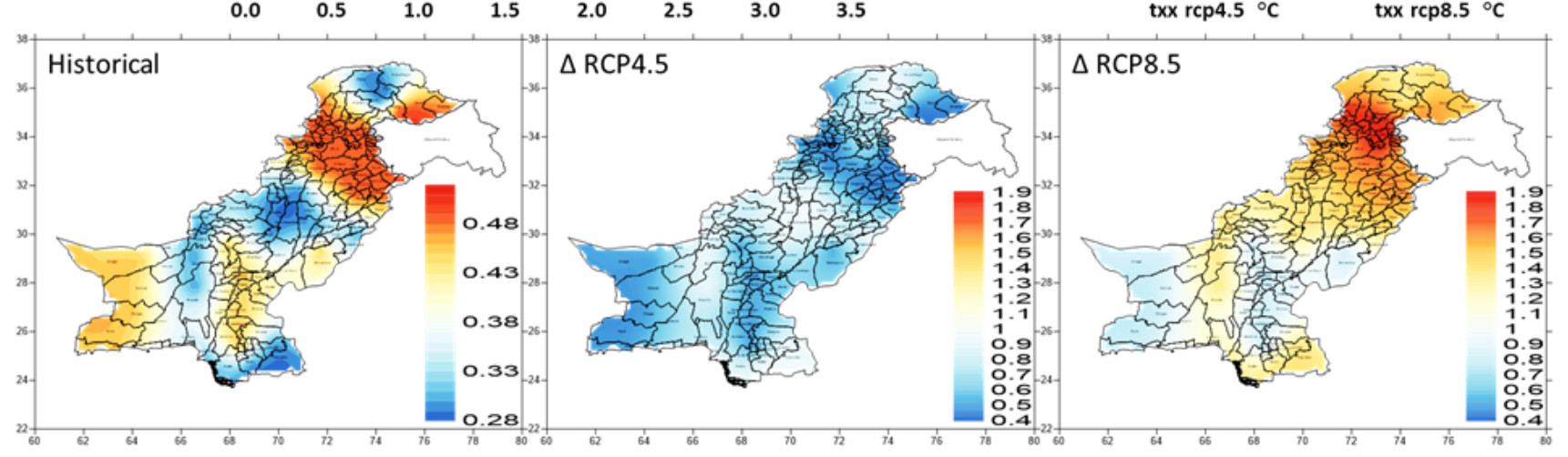

Figure 2. Univariate statistics of the TXX $\left({ }^{\circ} \mathrm{C}\right)$ based on historical and projected NEX-GDDP over Pakistan region

the TXX indicates that extremes of the warm daytime temperatures are projected to deviate significantly from the mean under both the emission scenarios of the future periods.

\section{Shifts in the SU25}

Figure 3 shows output of the computed statistics for the SU25. Historical SU25 index marks its $5^{\text {th }}$ percentile at 0.3 days and its $95^{\text {th }}$ percentile at 9.7 days as analyzed by univariate statistics. Under the RCP4.5 emission scenario, the $5^{\text {th }}$ percentile escalates its position by 5.4 days whilst the $95^{\text {th }}$ percentile carries it further by 14.8 days in the projected period. Under the high end RCP8.5 emission scenario, the $5^{\text {th }}$ percentile of the SU25 maintains at 5.4 days, whilst the $95^{\text {th }}$ percentile galvanizes that by 19.1 days. This extraordinary increase in the percentiles of the SU25 may be taken as a trigger for highly skewed distributions in the projected periods with supplementary days added to the existing summer days in the future projections.

Minimum number of the SU25 is computed as 0.3 whilst maximum number of those are computed as 9.7 in the historical period. Under the RCP4.5 emission scenario, minimum number of the SU25 is seen to increase significantly by 5.4 days whereas maximum number of the SU25 is seen to increase by a dominant 14.8 days in the projection period. Moreover, under the RCP8.5 emission scenario, the minimum (maximum) number of the SU25 is seen to further increase significantly by 5.4 (19.1) days in the future projections.
Increase in both minimum and maximum numbers of the SU25 forces expansion of summer season and at the same time contracts relatively milder spring and autumn seasons and hence directs adversity to hydrological and agricultural regime of a region.

Mean number of SU25 is 5.7 whereas median number of that is 7.2 in the historical period. The RCP4.5 emission scenario shifts both the mean and the median by 9.5 and 8.2 days respectively. It is interesting to note that under the RCP4.5 emission scenario there is a higher change in the mean of the SU25 than that in the median which suggests significant inclusion of extremes in the projected scenario. However, under the RCP8.5 emission scenario the median outstands the mean with changes of 18.2 and 13.7 days respectively. This means that under the high-end emission scenario, data density of summer days can potentially be skewed towards warmer side even without inclusion of extreme events and the whole of the distribution can experience warm shift with increased frequency over high magnitude bins.

The standard deviation of the historical SU25 is placed at 3.7 days with a consistent change under the RCP4.5 emission scenario. However, it ascends by 5.9 days under the RCP8.5 emission scenario which suggests a flattening behavior of a probability distribution with lengthier tails suggesting higher deviation of mean from extreme summer days. Behavior of range statistic is also consistent with pattern of standard deviation of the SU25 which indicates a range of 9.4 days in the 
SU (days)

Range: Standard Deviation:

\section{Median:}

Mean:

Maximum:

Minimum:

99\%\%-tile:

95\%\%-tile:

90\%\%-tile:

75\%\%-tile:

50\%\%-tile:

25\%\%-tile:

10\%\%-tile:

5\%\%-tile:

1\%\%-tile:
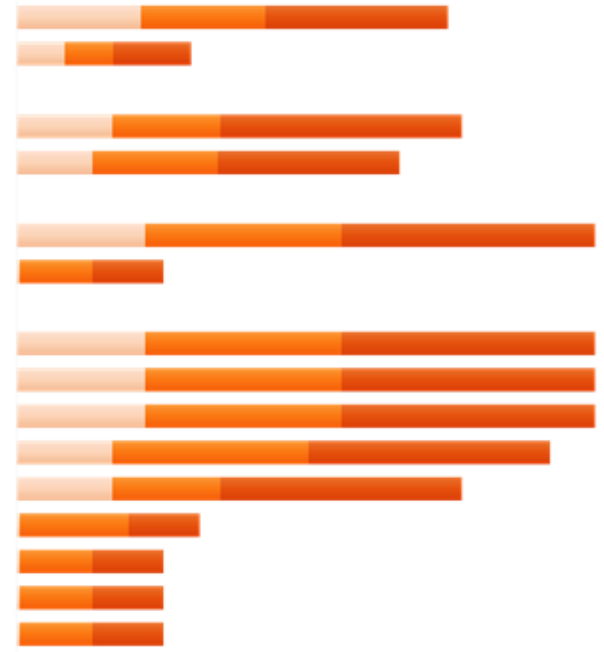

$\Delta$ Threshold (days)

25

20

15

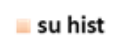

$\Delta$ su rcp4.5

$\triangle \mathrm{su}$ rcp8.5
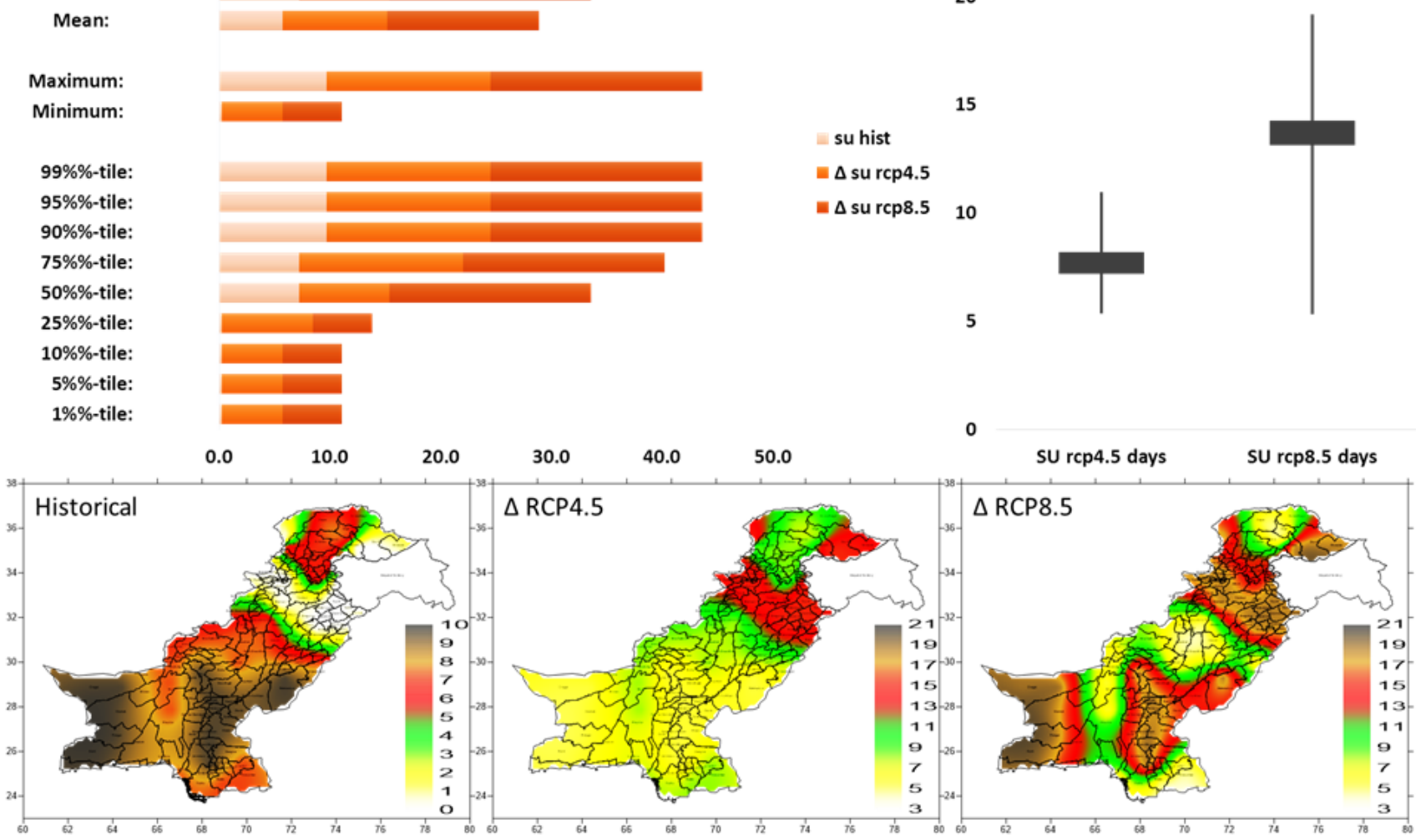

Figure 3. Same as in Figure 2 but for the SU25

historical period and a change of the same under the RCP4.5, as well as a range of 13.7 days under the RCP8.5 in the projected period.

\section{Shifts in the SDII}

Figure 4 shows output of the computed statistics for the SDII. The SDII has its $95^{\text {th }}$ percentile at $0.2 \mathrm{~mm} /$ day as depicted by the univariate statistics over the historical period. Interestingly, the SDII progresses by $0.6 \mathrm{~mm} /$ day in its $95^{\text {th }}$ percentile under the RCP4.5 emission scenario. The SDII under the RCP8.5 emission scenario bears no change with respect to historical period in its $95^{\text {th }}$ percentile as per the univariate statistics. The maximum SDII in the historical period exists at $0.2 \mathrm{~mm} /$ day, however, the RCP4.5 emission scenario pushes that up to $0.6 \mathrm{~mm} /$ day in the projection period. However, the SDII bears no changes in its $5^{\text {th }}$ percentile with respect to historical period. Changes in the higher percentiles strongly suggest notable increase in amount of precipitation and a simultaneous decrease in the number of wet days at wetter extremes of the SDII under the low-end emission scenario, whilst it advocates no significant difference when the highend emission scenario is analyzed.

The mean of the SDII is $0.1 \mathrm{~mm} /$ day in the historical period whereas it increases by the same magnitude under the RCP4.5 emission scenario. The RCP8.5 emissions scenario, however, pushes the mean down by $-0.04 \mathrm{~mm} /$ day in the SDII projection period. Median of the SDII is 0.03 in the historical period while it depreciates to null under the RCP4.5 emission scenario and projects no changes under the RCP8.5 emission scenario. These metrics of dispersion suggest no significant changes in the average SDII of the region.

To bring rationale to our investigation in differences seen under both the emission scenarios, the standard deviations and ranges over the analyzed periods are inspected. The historical standard deviation of the SDII is seen at 0.07 $\mathrm{mm}$ /day while a range of $0.2 \mathrm{~mm} /$ day is observed. Interestingly the RCP4.5 emission scenario spreads the SDII standard deviation by $0.4 \mathrm{~mm} /$ day and expands its range by $0.8 \mathrm{~mm} /$ day which explains its significant positive shift in the $95^{\text {th }}$ percentile under that scenario. An increase in the SDII can impact society by bringing potential disaster to agricultural activity as intense rain may not percolate to increase soil moisture, rather may become part of runoff to downstream environments.

\section{Shifts in the TN90p}

Figure 5 shows output of the computed statistics for the TN90p. The univariate analysis of the TN90p suggests that its $5^{\text {th }}$ percentile resides at 24.6 percent and the $95^{\text {th }}$ percentile at 26.4 percent over the historical period. Under the RCP4.5 emission scenario, the TN90p changes by 5.6 percent at its $5^{\text {th }}$ percentile and by 9.4 percent at its $95^{\text {th }}$ percentile in the projection period. More alarming situation is seen under the RCP8.5 emission scenario where changes of 16.5 percent in the $5^{\text {th }}$ and 19.7 percent in the $95^{\text {th }}$ percentiles are revealed in the TN90p future projections. Historically, the minimum of the 


\section{SDII (mm/day)}

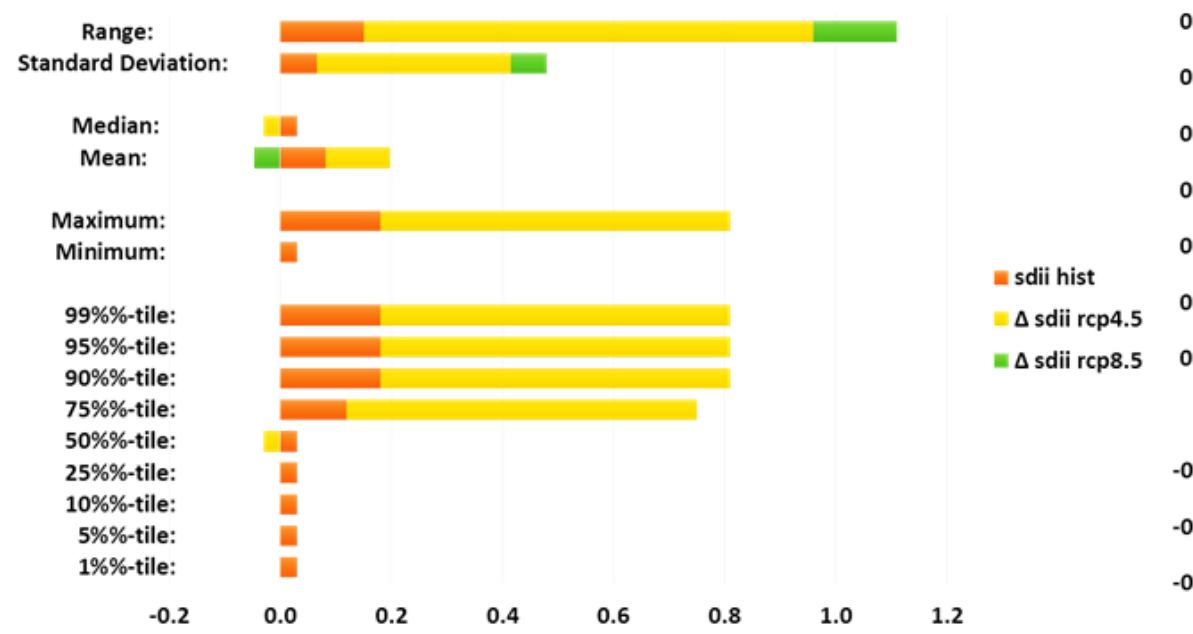

\section{$\Delta$ Societal Impact (mm/day)}

0.7

0.6

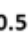

0.4

0.2

0.1

0

$-0.1$

$-0.2$

SDII rcp4.5 mm/day SDII rcp8.5 mm/day
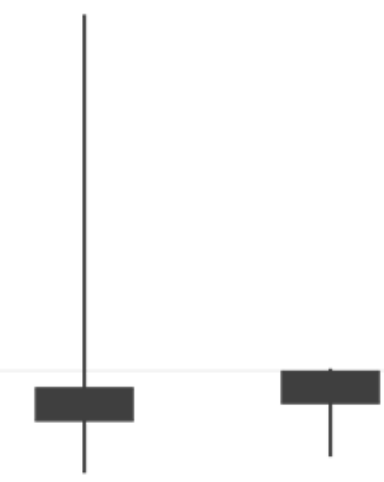

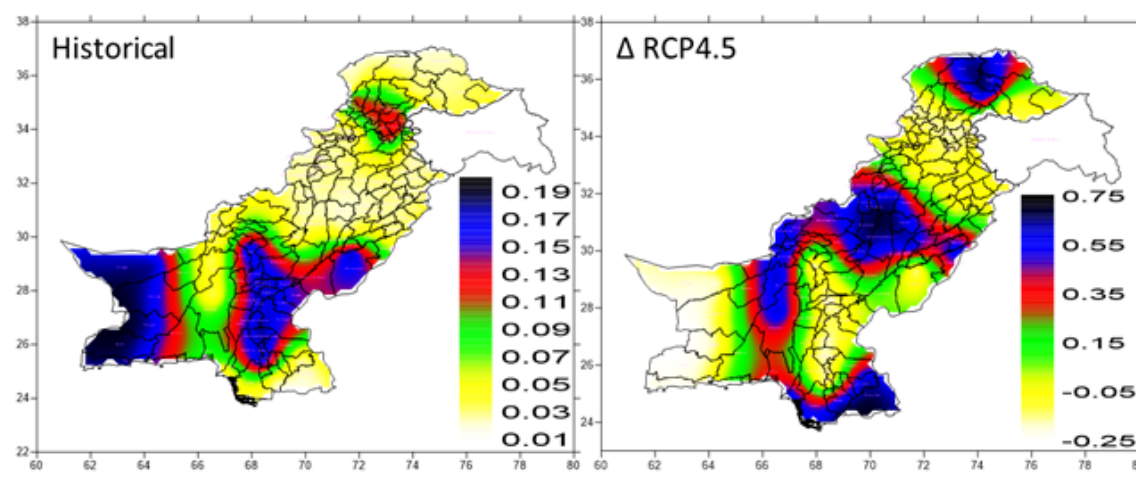

$\triangle \mathrm{RCP} 8.5$

Figure 4. Same as in Figure 2 but for the SDII

TN90p (\%)

$\Delta$ Percentile (\%)

Range:

Standard Deviation:

Median:

Mean:

Maximum:

Minimum:

99\%\%-tile:

95\%-tile:

90\%\%-tile:

75\%\%-tile:

50\%\%-tile:

25\%\%-tile:

$10 \% \%$-tile:

5\%\%-tile:

$1 \% \%$-tile:

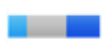

1 .
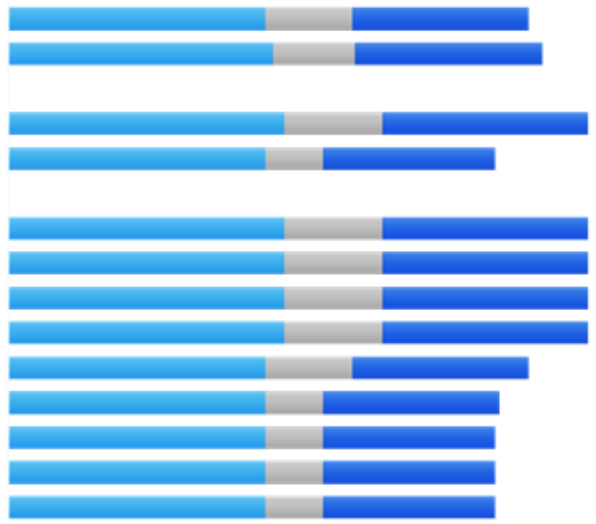

$\begin{array}{lllllll}0.0 & 10.0 & 20.0 & 30.0 & 40.0 & 50.0 & 60.0\end{array}$
20

$=$ tn90p hist

$\Delta \operatorname{tn} 90 \mathrm{p}$ rep4.5

$\Delta \operatorname{tn} 90 \mathrm{p} \operatorname{rep} 8.5 \quad 10$

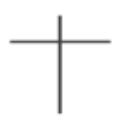

0

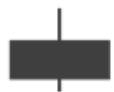

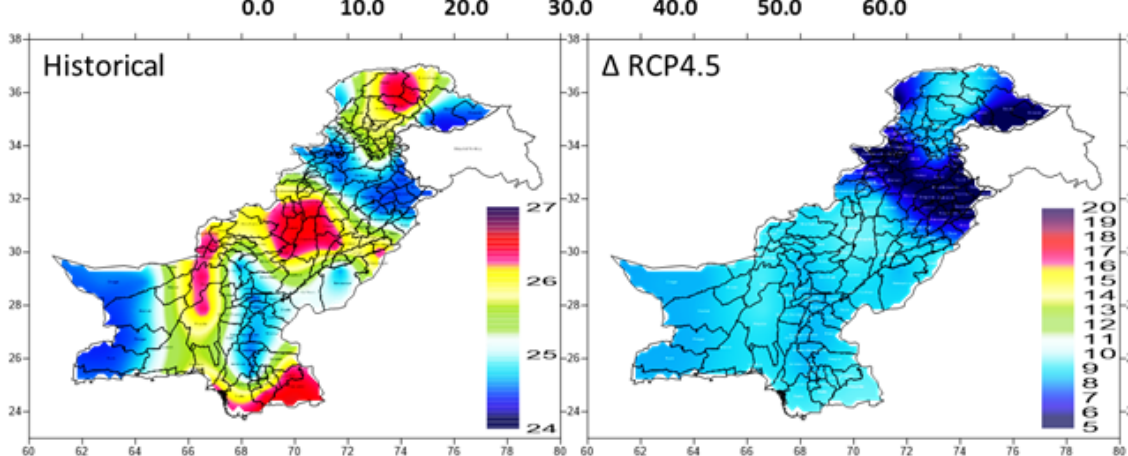

tn90p rcp4.5 (\%) $\quad$ tn90p rcp8.5 (\%)

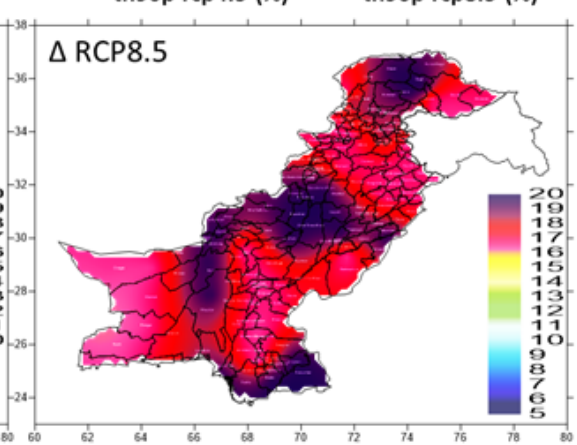

Figure 5. Same as in Figure 2 but for the TN90p 


\section{CDD (Days)}

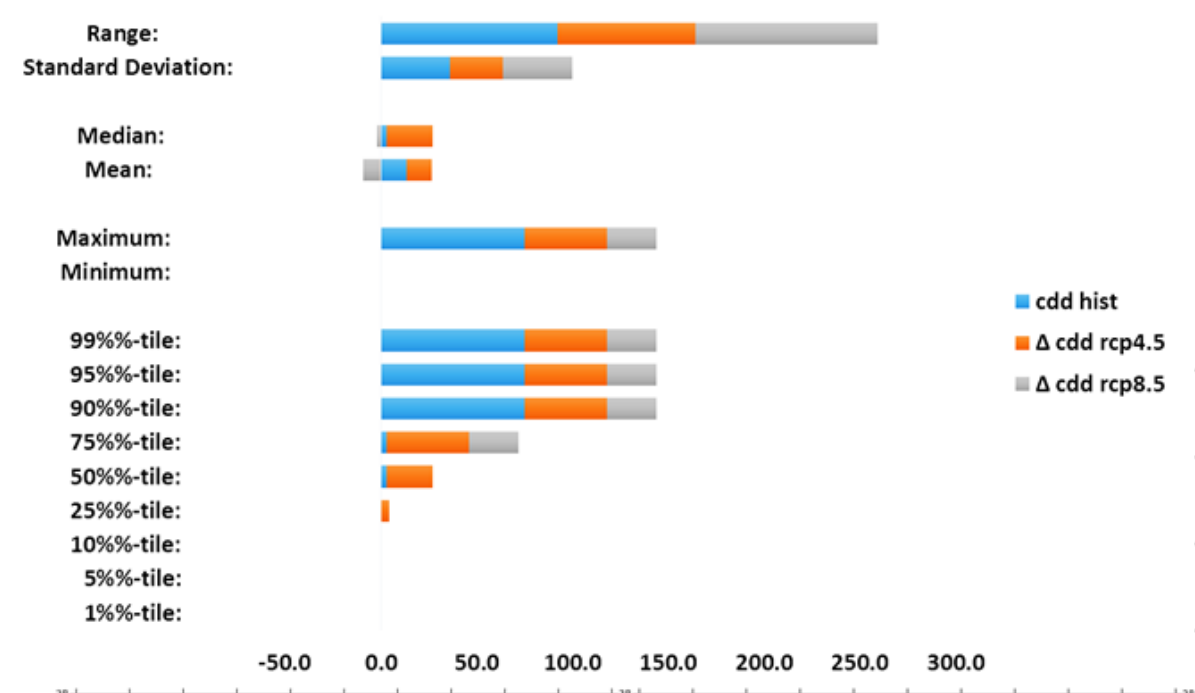

$\Delta$ Duration (Days)

60

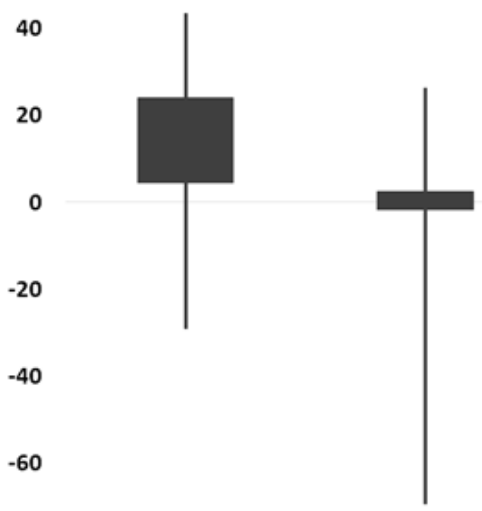

$-80$

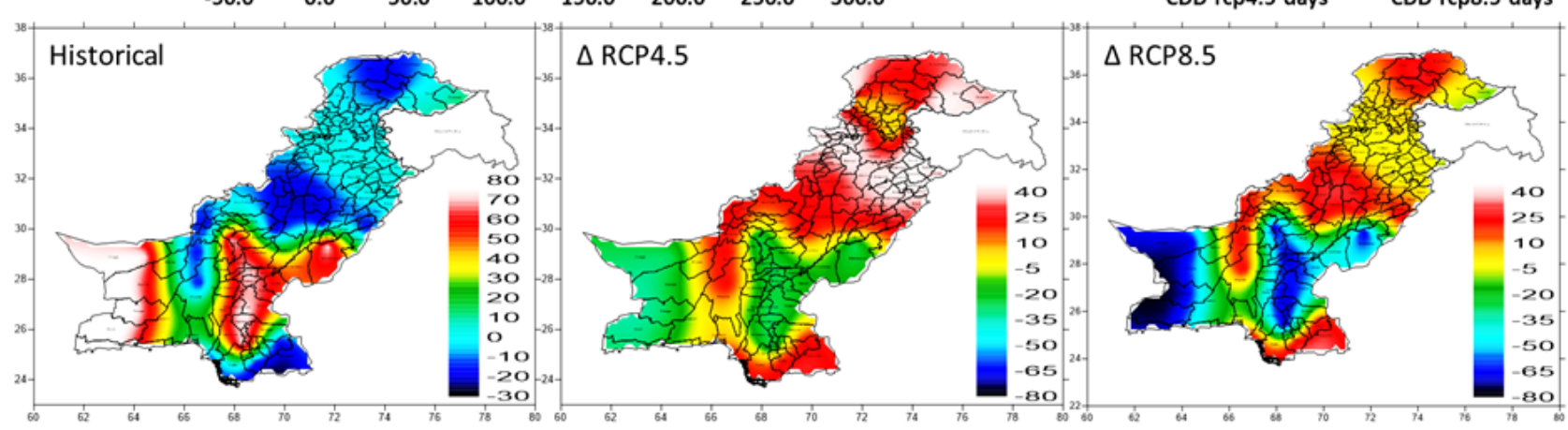

Figure 6. Same as in Figure 2 but for the CDD

TN90p exists at 24.6 percent whilst maximum of it points at 26.4 percent over the region. Warmer nighttime temperatures may present earlier frost-free dates and later first-frost dates, so pests control may become a challenge, and weeds can have more time to grow. Warmer nighttime temperatures may also increase transpiration from some crops, may dry them out, and may introduce crop health problems and lower yield.

Mean of the historical TN90p throughout the region is 25.3 percent whilst median of it is 24.6 percent as depicted by the univariate analytics. The mean (median) shifts by 7.9 (8.3) percent under the RCP4.5 emission scenario in the TN90p statistics. More prominent changes are seen under the RCP8.5 emission scenario with 17.9 percent shift in the mean and 16.9 percent shift in the median of the TN90p is seen. These significant differences in the TN90p may lead to increased risk of fire in certain areas of the region. Moreover, various molds, and rusts, on plants like cotton and wheat, are more likely to flourish in warmer night-time conditions.

Historical standard deviation of the TN90p resides at 0.8 percent whilst it shows an expansion of 1.5 percent under both the emission scenarios. The range statistic also deviates significantly with a value of 1.9 percent in the historical period to 3.8 (3.2) percent under the RCP4.5 (RCP8.5). Changes in both the standard deviation and the range statistics may allow larger spread in extreme warm nights that may recur with higher frequencies in the projection period. It also further establishes that effects of warmer nights may be far reaching which means that areas resilient to the effects of warm nights may experience discomfort as the period increases towards projections.

\section{Shifts in the CDD}

Figure 6 shows output of the computed statistics for the CDD. The $95^{\text {th }}$ percentile of the CDD is found at 75 days whilst it increases by 43 days under the RCP 4.5 and by 26 days under the RCP8.5. The maximum attainable CDD in the historical period is 75 days whilst it aggravates by 43 (26) days under the RCP4.5 (RCP8.5). Increased continuity in the farther extreme of the successive dry days is susceptible to bring prolonged drought periods at the stretch of the currently moist regions. This will further deteriorate water security from wet days in the region.

Mean historical CDD is 13.4 days and the median is 3 days which seems largely interesting. The mean of the historical period supersedes the median by almost 10 days which is quite large. This, along with the percentile-based statistics show that there are high value extremes in the historical CDD which significantly deviate mean from the median. As we progress further in to the projected period, the mean inflates by 13 days whilst the median does that by 24 days in the CDD under the RCP4.5. This means that there may exist an opposite pattern of the mean-median ratio in the future projections with almost double number of increased median days than those of mean under the RCP4.5. Although both the mean and the median are found to increase yet the influential effect of large values of the CDD may adhere to normality owing to its large difference in median values that can make the effect of the high values 
dormant under the RCP4.5 future projections. Under the RCP8.5, both the mean and the median may recess by -9.1 days and by -1.8 days respectively for the CDD univariate statistics. Higher decrease in the mean than that of the median under the RCP8.5 suggests that on a high-end emission scenario, both the mean and the median may nearly equate and be brought to historical state of the CDD.

The standard deviation of the CDD is 36 days with a range of 92 days in the historical period. It expands significantly by 27 days in the standard deviation and by 71 days in the range statistics of the CDD under the RCP4.5. Under the RCP8.5, the standard deviation expands by 36.4 days whereas the range deviates by an enormous 95 days in the projection period. This means that the spread of the CDD can be significantly higher in the future projections and more areas may be dominated by the influence of the $\mathrm{CDD}$ as the emissions progress.

\section{CONCLUSION}

Univariate analysis was performed on emissions forced NEX-GDDP dataset to detect projected changes in the ET-SCI based extremes over Pakistan region. Results revealed a substantial surge in the percentiles of the monthly maximum of the daily maximum temperature with significantly high median values. It prompted an environment where even in the absence of extreme events, the emissions-forced warmest daily maximum temperature was likely to propagate more than three times of that in the historical period over the studied region. An exceptional escalation in the percentiles of the summer days was found which could augment additional days to the prevailing summer days in the future projections. Our analyzed growth in both minimum and maximum sums of the summer days might trigger extension of summer season and at the same time diminish fairly milder spring and autumn periods. Deviations in both the standard deviation and the range statistics might sanction extension in extreme warm nights that were shown to persist with higher rates in the prognosis period. Moreover, effects of warmer nights could be far reaching which means that areas resilient to the effects of warm nights might experience discomfort as the period increases towards projections.

As was seen in the analyzed output, the simple daily intensity of precipitation increased that could have the potential to impact society by bringing prospective calamities to agricultural activity as intense rain could not percolate to increase soil moisture, rather might become part of runoff to downstream environments. Furthermore it was also seen through our analysis that the increased continuity in the farther extreme of the successive dry days might bring prolonged drought periods at the stretch of the currently moist regions. That could further deteriorate water and food security from around the region.

Author contributions: All co-authors have involved in all stages of this study while preparing the final version. They all agree with the results and conclusions.

Funding: No external funding is received for this article.

Declaration of interest: The authors declare that they have no competing interests.

Ethics approval and consent to participate: Not applicable.
Availability of data and materials: All data generated or analyzed during this study are available for sharing when appropriate request is directed to corresponding author.

\section{REFERENCES}

Abbas, S., Shirazi, S. A., Hussain, M. S., Yaseen, M., Shakarullah, K., Wahla, S. S. and Khurshid, M. (2020). Impact of climate change on forest cover: Implications for carbon stock assessment and sustainable development in HKH Region-Pakistan. Pakistan Vision, 21(1), 66.

Ahmad, W. (2020). Climate Change Assessment using Climate Indices Approach: A Brief Overview. International Journal for Research in Applied Science \& Engineering Technology, 8(9), 876-878. https://doi.org/10.22214/ijraset.2020.31604

Ahmed, I., Ullah, A., ur Rahman, M. H., Ahmad, B., Wajid, S. A., Ahmad, A. and Ahmed, S. (2019). Climate change impacts and adaptation strategies for agronomic crops. In Climate Change and Agriculture. IntechOpen. https://doi.org/10.5772/intechopen.82697

Ali, S., Eum, H. I., Cho, J., Dan, L., Khan, F., et al. (2019). Assessment of climate extremes in future projections downscaled by multiple statistical downscaling methods over Pakistan. Atmospheric Research, 222, 114-133. https://doi.org/10.1016/j.atmosres.2019.02.009

Ali, S., Saeed, A., Kiani, R. S., Muhammad, S., Khan, F., et al. (2021). Future climatic changes, extreme events, related uncertainties, and policy recommendations in the Hindu Kush sub-regions of Pakistan. Theoretical and Applied Climatology, 143(1), 193-209. https://doi.org/10.1007/ s00704-020-03399-7

Aslam, R. A., Shrestha, S., Pal, I., Ninsawat, S., Shanmugam, M. S. and Anwar, S. (2020). Projections of climatic extremes in a data poor transboundary river basin of India and Pakistan. International Journal of Climatology, 40(11), 49925010. https://doi.org/10.1002/joc.6501

Aziz, F., Tariq, N., Rahim, A. and Mahmood, A. (2021). Variability of Temperature Extremes in Northwest Himalayas during Early 21st Century (No. EGU21-394). Copernicus Meetings. https://doi.org/10.5194/egusphere-egu21-394

Betts, R. A., Alfieri, L., Bradshaw, C., Caesar, J., Feyen, L., et al. (2018). Changes in climate extremes, fresh water availability and vulnerability to food insecurity projected at $1.5 \mathrm{C}$ and $2 \mathrm{C}$ global warming with a higher-resolution global climate model. Philosophical Transactions of the Royal Society A: Mathematical, Physical and Engineering Sciences, 376(2119), 20160452. https://doi.org/10.1098/ rsta.2016.0452

Bhatti, A. S., Wang, G., Ullah, W., Ullah, S., Fiifi Tawia Hagan, D., et al. (2020). Trend in extreme precipitation indices based on long term in situ precipitation records over Pakistan. Water, 12(3), 797. https://doi.org/10.3390/ w12030797

Burhan, A. (2018). An analysis of climate change in Pakistan. Publisher: Scholar's Press. 
Burhan, A. and Shahid, M. (2017), Observed, simulated and projected extreme climate indices over Pakistan. Hamburg, Bedey Media GmbH. https://www.anchor-publishing.com/ document/371678

Chaudhary, Q. U. Z. (2017). Climate change profile of Pakistan. The Asian Development Bank.

Chaudhary, Q. Z. and Rasul, G. (2004). Agro-climatic classification of Pakistan. Science Vision, 9(1), 59-66.

Khan, N., Shahid, S., Ismail, T., Ahmed, K. and Nawaz, N. (2019). Trends in heat wave related indices in Pakistan. Stochastic Environmental Research and Risk Assessment, 33(1), 287-302. https://doi.org/10.1007/s00477-018-16052

Mukherjee, S., Aadhar, S., Stone, D. and Mishra, V. (2018). Increase in extreme precipitation events under anthropogenic warming in India. Weather and Climate Extremes, 20, 45-53. https://doi.org/10.1016/j.wace.2018. 03.005

Myhre, G., Alterskjær, K., Stjern, C.W. et al. (2019). Frequency of extreme precipitation increases extensively with event rareness under global warming. Scientific Reports, 9, 16063. https://doi.org/10.1038/s41598-019-52277-4

Qaisrani, A., Umar, M. A., Siyal, G. E. A. and Salik, K. M. (2018). What defines livelihood vulnerability in rural semi-arid areas? Evidence from Pakistan. Earth Systems and Environment, 2(3), 455-475. https://doi.org/10.1007/ s41748-018-0059-5

Rehman, N., Adnan, M. and Ali, S. (2020). Future Extremes and Variability of Rainfall over Monsoon Region of Pakistan. Pakistan Journal of Meteorology, 14(28), 61-78.

Saddique, N., Khaliq, A. and Bernhofer, C. (2020). Trends in temperature and precipitation extremes in historical (1961-1990) and projected (2061-2090) periods in a data scarce mountain basin, northern Pakistan. Stochastic Environmental Research and Risk Assessment, 34(10), 14411455. https://doi.org/10.1007/s00477-020-01829-6
Saeed, F. and Athar, H. (2018). Assessment of simulated and projected climate change in Pakistan using IPCC AR4based AOGCMs. Theoretical and Applied Climatology, 134(34), 967-980. https://doi.org/10.1007/s00704-017-2320-5

Sajjad, H. and Ghaffar, A. (2019). Observed, simulated and projected extreme climate indices over Pakistan in changing climate. Theoretical and Applied Climatology, 137(1), 255-281. https://doi.org/10.1007/s00704-0182573-7

Saleem, F., Zeng, X., Hina, S. and Omer, A. (2021). Regional changes in extreme temperature records over Pakistan and their relation to Pacific variability. Atmospheric Research, 250, 105407. https://doi.org/10.1016/j.atmosres.2020. 105407

Shultz, D. (2019). Extreme precipitation expected to increase with warming planet. Eos, 100. https://doi.org/10.1029/ 2019E0125869

Thrasher, B., Xiong, J., Wang, W., Melton, F., Michaelis, A. and Nemani, R. (2013). Downscaled climate projections suitable for resource management. Eos, Transactions American Geophysical Union, 94(37), 321-323. https://doi.org/10.1002/2013E0370002

Török, I., Croitoru, A. E. and Man, T. C. (2021). A new approach to assess the impact of extreme temperature conditions on social vulnerability. Natural Hazards and Earth System Sciences Discussions, 1-26. https://doi.org/10.5194/nhess2021-45

Watanabe, T., Cullmann, J., Pathak, C. S., Turunen, M., Emami, K., Ghinassi, G. and Siddiqi, Y. (2018). Management of climatic extremes with focus on floods and droughts in agriculture. Irrigation and Drainage, 67(1), 29-42. https://doi.org/10.1002/ird.2204

World Commission on Dams. (2000). Tarbela Dam and related aspects of the Indus River Basin in Pakistan. 